\title{
Choosing a Virtual World Platform for Teaching: "VICERO" - A Scoring Model Aiding the Right Choice
}

\author{
http://dx.doi.org/10.3991/ijac.v5i3.2192 \\ Kai Erenli \\ University of Applied Sciences bfi Vienna/Film, TV \& Media Production, Vienna, Austria
}

\begin{abstract}
When asking which Virtual World to use for educational purposes, people most often want to hear a onesentence answer. Frequently the question leads to a discussion that can be compared to a debate about religion: you cannot be too sure which side you will choose but you are easily doomed from the beginning if you pick the wrong side (or in this case, platform).
\end{abstract}

To help educators pick the right Virtual World platform we have developed a Scoring Model and Criteria Catalogue which support choosing the most suitable platform for teaching purposes. Educators can use the Scoring Model to rate the criteria based on their respective demand. The Scoring Model will then suggest a Virtual World platform from a "long list" and instruct the educator how to install/use/maintain the platform. Thus educators will not be left alone with their choice and will get a motivational hint where to start and where to seek support. The "long list" is monitored and updated regularly so that selections are always up-to-date.

Index Terms-Virtual Worlds, Scoring Model, VICERO.

\section{INTRODUCTION}

"There is no right and wrong. There's only fun and boring," said Fisher Stevens' character "Eugene Belford" in the 1995 movie "Hackers", whose tag line read, "Boot up or shut up!” Today's educators may find this familiar: on one hand they have to entertain their audiences aka students or staff, on the other hand they are meant to educate them in a proper manner.

Educators wanting to use tools of the so-called "new media" face a great challenge. Setting up a tool like a Virtual Environment for e-learning must be considered a long-term investment. Especially installation and customization require considerable time and know-how [1]. Moreover, knowledge of the tools e.g. Virtual Worlds available is also necessary. Many Virtual Worlds are still under heavy development, others may already be stable and mature but do not meet the requirements proposed by the educator. In the end many educators who started motivated and in good faith discontinue their effort to use a Virtual Environment for e-learning. Some educators did end up asking us for help since they did not want to surrender that easily. To be able to help them we began asking them questions, such as
1. What do you want to use the Virtual World for?

2. How many students do you want to reach?

3. What assignments/tasks will you give the students?

4. Do you have a server you can use? What does it run?

5. Do you have IT skills or someone who will help you set up the Virtual World?

Most often we got confused answers which led to long discussions. Even though we wanted to help the educators maintain their high level of motivation, we failed. Therefore, to respond to these kinds of questions more effectively, we created a checklist [1] which helped us plan the first steps. The checklist was well received by the educators but lacked one essential element: flexibility. It could only respond to model usage of Virtual Environments and did not address the different requirements of each educator. While some educators were already familiar with the technical demands of a Virtual Environment, they did not know how to present adequately to students or staff within the Virtual Environment. Other educators easily managed to present but did not know how to transfer files, etc. In the end we decided to develop a Scoring Model that would help them all - a Scoring Model that would react to each and every requirement, whether an educator wanted to use the Virtual Environment for team training, project management purposes or just simple distance learning presentations. It would also address the fact that different educators needed different tools and that different educators had different background knowledge of Virtual Environments. And thus "VICERO” was born.

\section{A TASK IS BORN}

When we asked educators why they wanted to use Virtual Environments in their teaching we predominantly got the answer that they were not satisfied with their slideshow presentations any more. Moreover, students demanded more distance learning elements in their courses. Doing research to find a solution for their problems, they had come across Virtual Worlds and their possibilities for educational purposes. When they approached us they demanded a one-sentence answer. Educators who needed a Virtual Environment/World for project management classes needed a meeting room, a place to present slideshows, a whiteboard and a tool to collaborate. Educators in need of a Virtual Environment/ World for job training courses wanted a world that was closed to the public, customizable and easy to learn. Educators in the field of law were asking for a setup where they could have a moot 
court, etc. Most often it was impossible to give good advice since the information provided was insufficient. Even if we gave advice, educators did not follow up. They simply could not handle an answer like "Go with Platform/Environment/World XY". On the other hand, we could not offer sufficient or suitable support since we did not have the necessary resources. Recognizing that this was not satisfying and sometimes even disturbing to the educators and us, we decided to come up with a solution. To begin with, we had to do some more research on the educators' motivation since it was evident that they had not been sent to seek advice from us by some greater spirit.

Many of the educators stated that they had heard something about "Gamification" [2] and wanted to join the ranks. While everyone familiar with Virtual Worlds knows about Gamification and its impact on e-learning, it was interesting to learn that even educators from the "other side" (those once skeptical of using new technologies for teaching purposes) seemed eager to try something new. This is important to acknowledge, as the "fun factor" of trying something new obviously hooked those educators too. Eugene Belford's line had already come true. It was all about "fun and boring".

Findlay and Alberts state that Gamification is "the integration of the mechanics that make games fun and absorbing into non-game platforms and experiences in order to improve engagement and participation."[3] This statement convinced us that we could use this momentum to develop something that would help educators take their first steps in an educational Virtual Environment and would add to our own research on Virtual Worlds. Since we had already developed a checklist, we could easily take this evaluated research as a starting point.

\section{AsKing The Right QUESTIONS}

We created a spreadsheet to collect the questions we had received from interested educators. Then we compared the questions from the spreadsheet with the checklist. Nearly $80 \%$ of the questions were already covered in the checklist, another $20 \%$ had to be added to obtain a helpful Criteria Catalogue for the Scoring Model. One aspect that had to be added was Gamification. Therefore one of the first tasks while developing the Criteria Catalogue was to implement Gamification as a criterion.

To provide a qualitative comparison of different Virtual Worlds, it is necessary first to determine key criteria by which to evaluate which worlds are considered relevant and which are negligible. The criteria selected were [see also 1]:

- administration/user groups,

- data security,

- resource sharing,

- communication/interaction tools,

- modifications/customizing,

- $\quad$ support (documentation, manuals, tutorials),

- costs/licensing,

- available languages,

- usability - client,

- $\quad$ assessment prerequisites (hardware, resources, ...),
- gamification relevance,

- project management relevance,

- e-learning relevance.

For each key criterion a set of relevant topics was created and addressed accordingly. Using this system makes it easy to add, change or delete topics without changing the entire key criteria catalogue. In addition, it also makes the Scoring Model flexible for the upcoming development process.

As soon as the Criteria Catalogue was complete, the decision was reached to make it available online. To this end, a website was created which had to be capable of meeting the following requirements:

- available 24/7

- easy to maintain

- flexible to respond to updates or new releases of Virtual Environments/Worlds

- easily connectable to tutorials

This task was assigned to a group of students who were permitted to design the realization on their own as long as the requirements mentioned above were fulfilled. The students were given a timeframe of two months to come up with a solution. They called their project "VICERO", which was then also chosen as the name for the Scoring Model itself.

TABLE I.

EXAMPLE OF CRITERIA CATALOGUE

\begin{tabular}{|c|l|c|c|}
\hline \multirow{2}{*}{} & \multicolumn{2}{|c|}{ Gamification-Related Criteria } \\
\cline { 2 - 4 } 1 & \multicolumn{1}{|c|}{ Criterion } & Rate & Points \\
\hline 2 & $\begin{array}{l}\text { achievement system / } \\
\text { target badge }\end{array}$ & 1 \\
\hline 3 & $\begin{array}{l}\text { virtual goods can be traded } \\
\text { / awarded }\end{array}$ & 2 \\
\hline 4 & avatars can show emotions & 3 \\
\hline 5 & FB, Twitter-API, etc. & 4 \\
\hline 6 & customization & 5 \\
\hline
\end{tabular}

Fig. 1: Example of Category Administration Features

TABLE II.

EXAMPLE OF CRITERIA CATALOGUE

\begin{tabular}{|c|l|c|c|}
\hline \multirow{2}{*}{} & \multicolumn{1}{|c|}{ IT-Related Criteria I (Administration A) } \\
\cline { 2 - 4 } & \multicolumn{1}{|c|}{ Criteria } & Rate & Points \\
\hline 2 & no user roles needed & 1 \\
\hline 3 & $\begin{array}{l}\text { no specific user roles needed } \\
\text { admin) needed }\end{array}$ & 2 \\
\hline 4 & $\begin{array}{l}\text { classified rules (user, admin, } \\
\text { co-admin) needed }\end{array}$ & 3 \\
\hline 5 & $\begin{array}{l}\text { individual user roles can be } \\
\text { defined }\end{array}$ & 5 \\
\hline 6 & $\begin{array}{l}\text { group-based rights needed } \\
\text { ruy }\end{array}$ & 6 \\
\hline
\end{tabular}

Fig. 2: Example of Category Administration Features 


\section{NOT ONLY GIVING ANSWERS}

When we thought about how to provide the best answer, we decided that just giving out a "name" was not an ideal solution. Educators still needed help and support to "pick up speed" in the Virtual Environment/World advised. For some Virtual Environments/Worlds it is easy to provide a link to the respective support website, but for some others like "openQwaq" this is not very helpful. Educators who want to install a web server on their own need advanced IT skills or at least someone competent helping them. It simply is not satisfying to be left with nothing but the answer "Try Virtual World/Environment $\mathrm{XY}$ ”. Based on our experience with various project groups that a "no-one-gets-left-behind" rule [see 1] aids user commitment in a Virtual Environment/World, it was evident that educators had to be given a follow-up. To this end, a tutorial was created for each Virtual Environment/World and connected to the Scoring Model.

Ultimately the advice educators receive when they have filled out and rated every criterion in the Scoring Model consists of three elements:

1. A shortlist of proposed Virtual Environments/ Worlds

2. A short summary of each Virtual Environment/ World

3. A "first-steps" tutorial for each Virtual Environment/World

It is important to monitor and evaluate each Virtual Environment or World regularly since each change, development or termination will impact the Scoring Model. As it is important to a non-profit organization like us to keep an eye on maintenance costs, we decided to "outsource" the "first-steps" tutorial for the Scoring Model, the reason being that it is nearly impossible to provide support for each and every Virtual Environment or World. So typically the "first-steps" tutorial will guide the user to the support site of the Virtual Environment or World. If available, personal remarks (e.g. "Use a CentOS operating system for the server, but make sure that it is version 2.x") are given on the side. This process is always seen in connection with the "no-one-gets-left-behind" rule. The students maintaining the tutorials have to ask themselves every time they write or update a tutorial, "Will I be able to use the Virtual Environment/World with the information given in the tutorial?”

The tutorials trace back to tutorials written by student project teams for team members who needed guidance. Therefore a lot of evaluating has already taken place and most of the tutorials do not need much improvement. On the other hand, many tutorials have to be written new and every tutorial must be considered a "work in progress". This results in the fact that we do have back-to-back project monitoring for the tutorials as well as the Virtual Environments and Worlds. Feedback on the tutorials will also be collected and forwarded to this project group.

\section{CONCLUSION}

Considering that Virtual Environments or Worlds are not just hype within the e-learning community, it was frustrating to see that many motivated educators failed when they tried to use a Virtual Environment/World, which then resulted in once motivated educators giving Virtual Environments/Worlds a bad name. Therefore, the
Scoring Model project was not only considered a good idea but was also popular with the students who had to come up with ideas to build VICERO.

Based on the results of former research it was easy to come up with the relevant data to develop the Scoring Model. The fact that many educators mentioned gamification as a motivational factor was inspiring to the development process itself. Therefore a gamification rule was added to the project goals: "The Challenge and Complexity of the Catalogue has to be seen in relation to the skill of the user to use it. It should not be too challenging or too easy, so the engagement of the educator to use it remains on a high level." [3] Although it was not planned to give out achievement points or badges to those using the checklist, this was considered to add gamification-related content to the Scoring Model itself. So, more experienced users of the Scoring Model should be able to "level up" and become "VICERO Ambassadors". This idea was abandoned during the design process as it became clear that this task would take up too many resources. The gamification rule also helped implement knockout criteria in the Scoring Model. This will aid educators who cannot be given advice suitable for their requirements. It was well considered that the answer "Sorry, no suitable Virtual Environment/World could be found for your requirements" would also be helpful for educators. It does put a stop to their search but simultaneously helps them focus on other tools like classic e-learning platforms or even offline practices. Nevertheless VICERO will suggest a set of basic Virtual Environments/Worlds to look at.

As shown, VICERO can be seen as work in progress, since the Scoring Model is only released for public testing and the mechanics of the Scoring Model itself are rather simple. Educators' different skill levels are also considered a big challenge for VICERO. Therefore, the tutorials need intensive testing by the different kinds of educators in the field and feedback is greatly appreciated. The translation into other languages also is on a "would-benice-to-have" list. As VICERO is made available to the public it can be found at http://vicero.virtuellewelten.at. Using the Scoring Model is free of charge, but no warranty is given to educators following its advice. What is also worth mentioning is that the people maintaining VICERO have no commercial affiliation with any of the providers of Virtual Environments or Worlds. All advice given by VICERO is based on a neutral assessment of the Environments/Worlds

\section{Hopefully VICERO will help}

- to eliminate barriers to the use of Virtual Environments/Worlds for learning,

- to make the right choice when selecting a Virtual World platform for e-learning, and

- to take first steps on "alien" ground,

because in the end it is not about "right or wrong" but about "fun or boring".

\section{ACKNOWLEDGMENT}

Acknowledgments are given to the various student project teams who have helped develop VICERO and the tutorials (and who have also come up with the name). 


\section{REFERENCES}

[1] K. Erenli and G. Ortner, "Collaborative and Social Learning using Virtual Worlds: Preparing Students for Virtually Anything” (iJAC), Vol 4, No 3 (2011), pp. 23-29.

[2] S. Deterding, D. Dixon et al, Gamification: Toward a Definition.

[3] K.Findlay and K. Alberts, Gamification, Future or Fail? http://www.slideshare.net/ervler/gamification-future-or-fail.

\section{AUTHOR}

Erenli, Kai works at the University of Applied Sciences bfi Vienna as Director of the Department of Film, TV and Media Production, A-1030 Vienna, Austria (email: kai.erenli@fh-vie.ac.at).

This article is an extended version of a paper presented at the conference ICELW2012, held June 2012, at Columbia University, in New York, NY, USA. Manuscript received 02 April 2012. Published as resubmitted by the author 05 August 2012. 